This item was submitted to Loughborough's Research Repository by the author.

Items in Figshare are protected by copyright, with all rights reserved, unless otherwise indicated.

\title{
Fuel consumption and emission reduction by using a CVT in series with conventional multi-speed transmission
}

PLEASE CITE THE PUBLISHED VERSION

https://doi.org/10.1504/IJPT.2019.099632

\section{PUBLISHER}

(C) Inderscience

\section{VERSION}

AM (Accepted Manuscript)

\section{PUBLISHER STATEMENT}

This paper was accepted for publication in the journal International Journal of Powertrains and the definitive published version is available at https://doi.org/10.1504/IJPT.2019.099632.

\section{LICENCE}

CC BY-NC-ND 4.0

\section{REPOSITORY RECORD}

Walker, Jack, I. Medina Huerta, Callum Oglieve, Rickie Bewsher, and Mahdi Mohammad-Pour. 2019. "Fuel Consumption and Emission Reduction by Using a CVT in Series with Conventional Multi-speed Transmission". Loughborough University. https://hdl.handle.net/2134/36280. 


\title{
Fuel Consumption and Emission Reduction by Using a CVT in Series with Conventional Multi-Speed Transmission
}

\author{
J. Walker, I. Medina-Huerta, C. Oglieve, S.R. Bewsher, M. Mohammadpour \\ Wolfson School of Mechanical, Electrical and Manufacturing Engineering, Loughborough \\ University, Loughborough, UK, LE113TU
}

\begin{abstract}
Fuel economy is a growing concern for both manufacturers within the automotive sector and consumers. Increasing government legislation is driving towards greener vehicles with reduced $\mathrm{CO}_{2}$ and $\mathrm{NOx}$ emissions and greater fuel economy, especially within urban environments. Manufacturers use new technologies in their powertrain systems to tackle these problems. This paper simulates and evaluates the performance of using a half toroidal CVT in series with a conventional multi-speed transmission, by analysing different shifting strategies to optimise fuel consumption and NOx emissions over the NEDC using this novel approach. The results show an $8.83 \%$ increase in fuel economy and up to an $11.34 \%$ reduction in NOx emissions is possible using this arrangement. The introduction of CVT adds a further $1.18 \%$ increase in fuel economy and $3.59 \%$ decrease in NOx emissions. The paper concludes that this novel arrangement should be considered by automotive manufacturers as a solution for improvements to powertrain technology.
\end{abstract}

\section{Keywords}

Toroidal CVT, Optimum Gear Ratio, Fuel consumption, Nitrogen Oxide Emissions, New European Driving Cycle

\section{Introduction}

In 2013 the transport sector was accountable for approximately $26 \%$ of greenhouse gases emitted in the UK [1]. The UK government has targeted consumers with financial incentives to purchase new cars emitting less than 95 grams $\mathrm{CO}_{2} / \mathrm{km}$ by introducing a Vehicle Excise Duty (VED), which entitles vehicles that emit less than 95 grams $\mathrm{CO}_{2} / \mathrm{km}$ an exemption from the levy, aiming to reduce overall $\mathrm{CO}_{2}$ emissions 
by $34 \%$. A study by Holmberg et al. [2] found that approximately $33 \%$ of fuel used in passenger vehicles is used to overcome mechanical friction, which for a 2010 passenger car equates to roughly 340 litres of fuel per annum.

Many strategies have been used to optimise the fuel efficiency of Internal Combustion Engines (ICEs) and powertrain systems. Technology such as fuel direct injection (DI), has been developed to improve overall fuel economy in ICEs by up to $20 \%$ [3], where the fuel is injected straight into the combustion chamber. Modern automotive manufacturers often turn to engine downsizing to improve fuel economy, whereby a turbo or supercharger is often used to increase the Indicated Mean Effective Pressure (IMEP) while reducing the engine capacity. Downsizing was not only proven to decrease fuel consumption over the NEDC cycle but also improve emissions [4, 5].

Variable compression ratios combined with variable valve actuation technology have also been shown to reduce fuel consumption by up to $13 \%$ over various drive cycles including the NEDC [6]. Cylinder Deactivation (CDA) and Stop/start have also been used by manufacturers to improve fuel consumption $[7,8]$.

A possible method to reduce $\mathrm{CO} 2$ emissions of a Rear Wheel Drive (RWD) vehicle is to add a Continuously Variable Transmission (CVT) in series with a conventional 5 speed gearbox. A CVT is a device that allows the ratio of the speeds of the driven shaft and the driving shaft to be altered, within a range governed by its physical geometry, infinitely. The implementation of a single cavity half toroidal CVT could allow the engine to operate in the most fuel-efficient or reduced NOx emission regions for longer because of the continuous transmission ratios that it permits opposed to discrete. Moreover, a clutch mechanism could be used to bypass the CVT and only use the 5-speed transmission, when the internal power loss of the CVT compromises the improvement of fuel consumption or reduced NOx emissions.

Research into geometrical optimisation of a toroidal CVT has shown greater efficiencies are achieved when the Elastohydrodynamic Lubrication (EHL) oil temperatures and rotational velocities of the input disk are both low [9]. When designing a toroidal CVT rolling fatigue life and maximum contact stress on the roller surfaces and disks must be considered [10]. Moreover, full and half toroidal CVTs 
have been compared, finding the latter has an efficiency advantage over full toroidal CVTs, because the spin losses are less [11]. When the CVT is in use, there is an EHL rolling contact between the disk and the roller, inducing boundary and viscous friction due to the thin lubricant film. Power loss is induced within the contact, decreasing the overall efficiency of the torque transmission.

This paper investigates a CVT in series with a 5-speed gearbox. A system level model of a vehicle was developed to investigate gear shifting strategies and optimisation of gear ratios. The model simulated fuel consumption and NOx emissions over any given speed trace. A component level model of a single cavity half toroidal CVT is developed. The component level model is used to predict several parameters including boundary and viscous friction calculating the power loss due to spin. The maximum sub-surface shear yield stress, calculated from pressure within the contact, has been used as a limiting factor as to whether the use of the CVT will cause excessive surface wear and pitting of the cavity and roller. The simulation calculates the optimal gear ratios of a half toroidal single cavity CVT in series with a 5-speed gear box, further improving fuel economy and reducing NOx emissions.

\section{System Level Model}

The system level model describes the kinematic model of the transmission ratio of a 5 or 6 -speed gearbox, and the optimisation of individual gear ratios. A separate calculation is required for the first gear ratio as it has set criteria to achieve such as hill starts. In addition to this, the top gear ratio will be selected with consideration of the legal maximum road speeds in the UK. All emission tests to date require a speed trace to be followed by a driver. There is a slight allowance for deviations from the target speeds; however, this simulation will follow the speed trace exactly. This is because the torque required of the engine will be back calculated from the velocity of the wheel. The simulation also considers CVT in series with the transmission.

\subsection{Half Toroidal CVT:}

The basic functionality of a toroidal CVT is as follows: an input disk has the angular velocity equivalent to that of the engine speed. The input disk is in contact with multiple rollers, which are used to transmit torque to the output disk. The rollers 
change the angle at which it lies between the input and output disk, either increasing or decreasing the speed of the output disk. The lubrication in the disk - roller conjunction is paramount to its efficient operation. A very high load is required for the rollers to transmit torque from one disk to another. resulting in the formation of an EHL film. The toroidal CVT allows for greater performance in terms of driveability and comfort for passengers in comparison to 5-speed transmissions, which greatly benefits urban driving environments where there is greater transients. A kinematic model is used to describe the transmission ratio of the CVT, requiring material selection for the disks and rollers to allow for sufficient durability of the system. The system geometry is defined in Figure 1 and 2, and the parameter inputs used in the simulation are displayed in Table 1.

\section{CVT Transmission Ratio:}

The transmission ratio of the CVT is assumed to be ideal for the preliminary simulation, where the ideal ratio is calculated using:

$i=\frac{\mathrm{R}_{3}}{\mathrm{R}_{1}}=\frac{\mathrm{e}-\cos (\mathrm{q}-\mathrm{f})}{\mathrm{e}-\sin (\phi)}$

Where $\phi$ is the possible angle and $e$ is the minimum radius of the disk.

In reality, creep occurs when there is a velocity difference $\left(V_{1}-V_{2}\right)$ between the roller and disk (1), and thus must be taken into consideration;

$$
c r_{\text {in }}=\frac{V_{1}-V_{2}}{V_{1}}=\frac{\omega_{1} R_{1}-\omega_{2} R_{22}}{\omega_{1} R_{1}}
$$

Where $\omega_{1}$ is the angular velocity, $R_{1}$ is the input radius and $R_{22}$ the radius of the roller. 


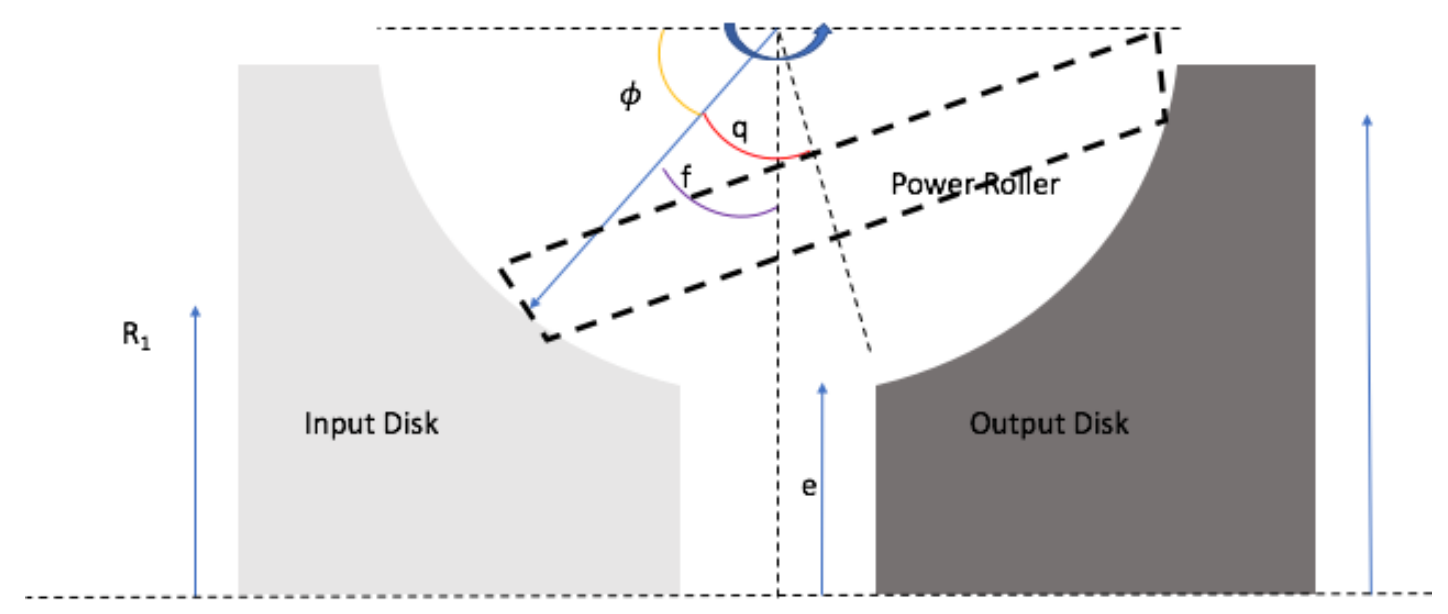

Figure 1: Defined Geometry of a Toroidal CVT

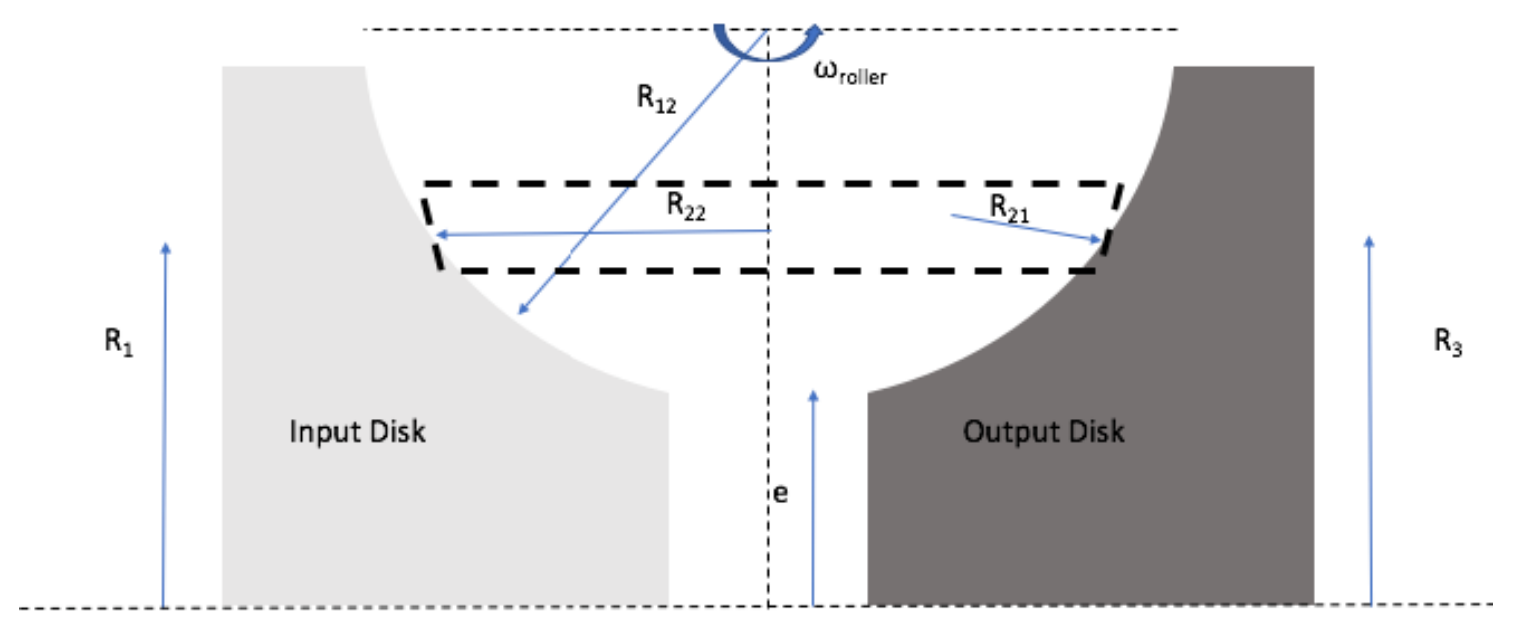

Figure 2: Additional Defined Geometry of a Toroidal CVT

\begin{tabular}{|c|c|c|c|c|c|}
\hline \multicolumn{2}{|c|}{ Parameter } & \multirow{2}{*}{ Definition } & \multicolumn{2}{|c|}{ Parameter } & \multirow{2}{*}{ Definition } \\
\hline Symbol & Unit & & Symbol & Unit & \\
\hline $\mathrm{R}_{1}$ & $\mathrm{~m}$ & Input Radius & $\mathrm{R}_{12}$ & $-0.040 m$ & Radius of the Cavity \\
\hline $\mathrm{R}_{3}$ & $\mathrm{~m}$ & Output Radius & $\mathrm{R}_{21}$ & $0.0202 \mathrm{~m}$ & Roller Curvature \\
\hline$q$ & Rads & $\begin{array}{l}\text { Half Cone Angle } \\
\text { of the Roller }\end{array}$ & $\mathrm{R}_{22}$ & $0.032 \mathrm{~m}$ & Radius of the Roller \\
\hline$f$ & Rads & Roller Tilt Angle & e & $0.025 \mathrm{~m}$ & $\begin{array}{l}\text { Minimum distance from } \\
\text { toroidal centre to cavity } \\
\text { edge }\end{array}$ \\
\hline
\end{tabular}




\section{Material Selection for CVT:}

The criterion for the material for the CVT's roller and disk are like that of a bearing [10], such that it should be; high hardness, good wear resistance, high rolling fatigue strength, operation temperature should be up to $200^{\circ} \mathrm{C}$, smooth surface finish and corrosion resistant. Therefore, AISI 52100 Steel has been chosen with material composition shown in Table 2 and thermal properties in Table 3.

Table 2: AISI 52100 Composition
\begin{tabular}{|l|l|l|l|l|l|l|}
\hline SAE 52100 Composition \\
\hline C & Si & Mn & Cr & P & S & Application \\
\hline $0.98-1.1 \%$ & $\begin{array}{l}0.15- \\
0.30 \%\end{array}$ & $\begin{array}{l}0.25- \\
0.45 \%\end{array}$ & $1.3-1.6 \%$ & $0.025 \%$ & $0.025 \%$ & $\begin{array}{l}\text { Bearings } \\
\text { typically }\end{array}$ \\
\hline
\end{tabular}

Table 3: Mechanical Properties of AISI 52100

\begin{tabular}{|l|l|l|l|l|l|l|}
\hline \multicolumn{5}{|l|}{ SAE 52100 Mechanical Properties } \\
\hline Density & $\begin{array}{l}\text { Specific } \\
\text { Heat }\end{array}$ & $\begin{array}{l}\text { Thermal } \\
\text { Conductivity }\end{array}$ & $\begin{array}{l}\text { Young's } \\
\text { Modulus }\end{array}$ & $\begin{array}{l}\text { Yield } \\
\text { Strength }\end{array}$ & $\begin{array}{l}\text { Poisson's } \\
\text { Ratio }\end{array}$ & $\begin{array}{l}\text { Hardness } \\
\text { (Rockwell) }\end{array}$ \\
\hline $\mathrm{g} / \mathrm{cm}^{3}$ & $\mathrm{~kJ} / \mathrm{kg} \cdot \mathrm{k}$ & $\mathrm{W} / \mathrm{m} . \mathrm{K}$ & $\mathrm{MPa}$ & $\mathrm{MPa}$ & & HRC \\
\hline 7.83 & 0.46 & 43 & 201 & 1410 & 0.28 & $62[14]$ \\
\hline
\end{tabular}

Rear Wheel Drive Transmission: The model utilises a rear wheel drive transmission. A rear wheel drive model has enough space between the transmission and the differential. The CVT could be an additional unit installed in front of the main transmission with a clutch pack in front. If the half-toroidal CVT was packaged in a compact manner, it could be placed with the transmission tunnel itself. For a standard RWD transmission layout, the torque of the engine is transmitted via a clutch to the input shaft. However, in the simulation the torque from the engine is transmitted via an engaged clutch to the CVT. The output disk will then transmit the torque to an input shaft of a fixed gear ratio, thus transferring torque to a lay-shaft. The lay-shaft in turn drives different pairs of gears dependent on which gear is selected. The output from the final gear passes the torque to the driveshaft, which transfers the torque to a differential. The torque is multiplied by the ring gear and transferred to the back two wheels [15].

The rotational speed of the rear wheels and torque are: $T_{w}=\varphi_{\text {Input }} \varphi_{C V T} \varphi_{\text {Gear }} \varphi_{\text {Diff }} T_{E n g}$ 
$N_{w}=\frac{N_{E n g}}{\varphi_{\text {Input }} \varphi_{\text {Gear }} \varphi_{\text {Diff }} R_{C V T}}$

To simplify the simulation the overall gear ratios will be calculated instead of the individual gear ratios.

$T_{w}=T_{E n g} \varphi_{C V T} \varphi_{n} \eta$

$N_{w}=\frac{N_{E n g}}{\varphi_{n} \varphi_{C V T}}$

\subsection{Vehicle Longitudinal Dynamics:}

Equation 7 is used to simulate the vehicle's longitudinal dynamics [16]:

$\sum F=M_{v} a=F_{x}-\left(F_{D}+F_{R}+F_{G}\right)$

where, $F_{x}$ is the tractive force, $F_{D}$ aerodynamic drag, $F_{R}$ the resistance to rolling and $F_{G}$ is any loading due to a gradient of the road. This is also shown in Figure 3.

The traction force is to include the drivetrain inertias. If drivetrain inertias were not considered, there would be an underestimation of the fuel consumption and the amount of NOx emitted [16]:

$F_{x}=\frac{T_{E n g} \mathrm{R}_{\mathrm{CVT}} R_{n} \eta}{r_{w}}-\frac{a}{r_{w}^{2}} I_{E f f}$

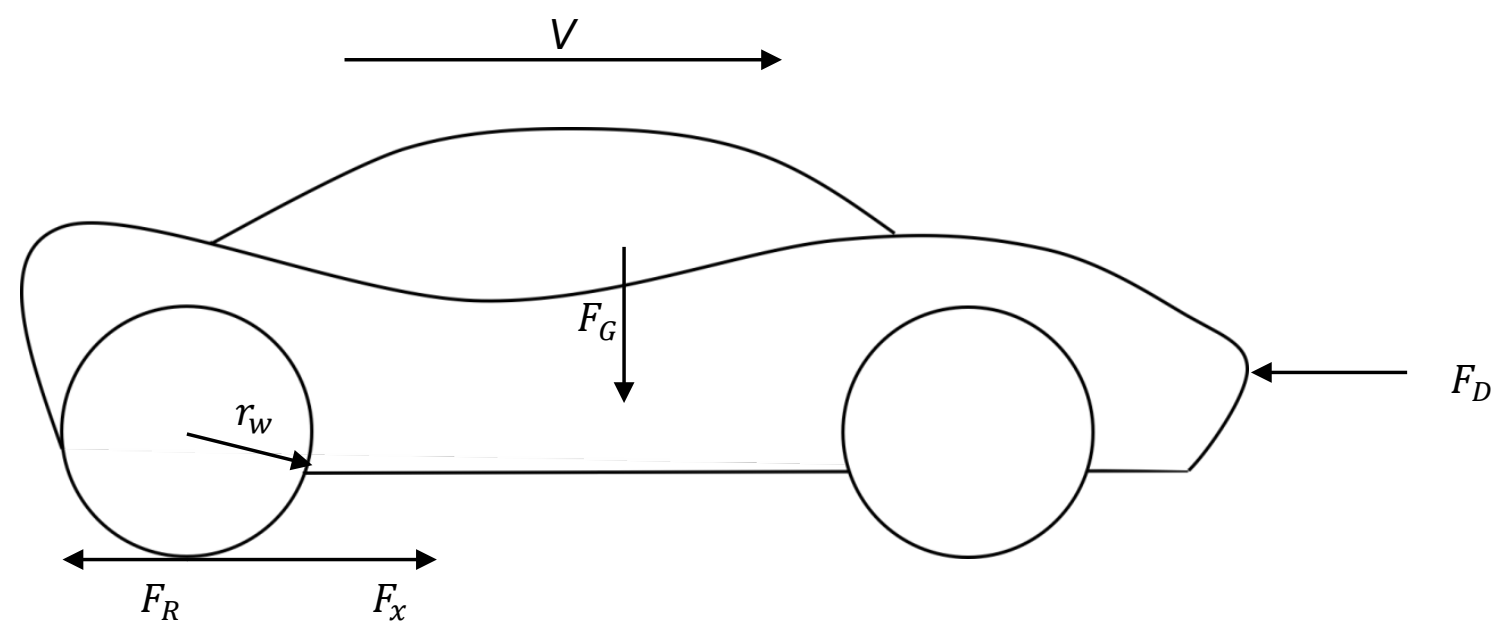

Figure 3: Free Body Diagram of Rear Wheel Drive Vehicle

The inertia stated in equation 8 is calculated via:

$I_{E f f}=\left(I_{E}+I_{F, C}+I_{T, i n}\right)\left(\varphi_{\mathrm{in} n} \varphi_{n} \varphi_{F . D}\right)^{2}+I_{T, \text { lay }}\left(R_{n} R_{\mathrm{F} . \mathrm{D}}\right)^{2}+\left(I_{\mathrm{T}, \mathrm{out}}+I_{\mathrm{P}}\right) \varphi_{\mathrm{F} . \mathrm{D}}{ }^{2}+I_{\mathrm{D}}+\mathrm{I}_{\mathrm{S}}+$ $\mathrm{I}_{\mathrm{W}}$

The aerodynamic drag, rolling resistance, and coefficient of friction considered are [16]: 
$F_{D}=\frac{1}{2} c_{D} \rho A_{f} v^{2}$

$F_{R}=\mu M_{v} g \cos \theta_{\text {road }}$

$\mu=0.01\left(1+\frac{2.23694 \mathrm{v}}{147}\right) \theta_{\text {road }}>0:$ uphill gradient

The loading due to the gradient of the road is:

$F_{G}=M_{v} g \sin \theta_{\text {road }}$

However, during chassis dynamometer tests there are no gradient compensations considered and so $F_{G}=0$ in that case.

\subsection{Gear Ratio Selection Considerations:}

First gear must have a high enough torque transmission to guarantee the vehicle's hill start from at least a $33 \%$ gradient [17]. In first gear a creep speed is expected to negate unwarranted clutch usage in congested driving scenarios [18]. When considering Equation 13, as the gradient increases positively, the force required to overcome the loading, due to gradient of the road, increases.

Top gear selection targets optimal fuel consumption and NOx emissions rather than the achieving greater maximum speeds. For legal UK motorway speed limits, the top vehicle speed is $70 \mathrm{mph}$, which has been factored into calculation of the top gear ratio. The BSFC map of the engine selected shows the best fuel economy figures will be achieved near full load between 2000 and 3000 rpm.

\subsection{Gear Shifting Strategy:}

The shifting strategy focuses on either best fuel economy or NOx emissions. A series of nested loops are utilised to find the impact of changing an individual gear ratio and ultimately achieve the optimised solution for the transmission system. This strategy also incorporates a set limit for the engine speed to remain within idle and max engine speed. The torque curve of the vehicle is used to define the maximum torque limit at any given engine speed, assuming that during the drive cycle the transmission would follow a strategy to minimise either NOx or fuel consumption.

\subsection{Component Level Model:}

The component level model of the CVT predicts the power loss at a specified torque and engine speed to only use the CVT when it is beneficial to the fuel economy. Moreover, the model accounts for the durability of the CVT. The contact between the disks and the rollers cause power loss due to the generation of boundary and viscous friction, limiting the durability of the component. The sub-surface stresses could surpass their elastic limit if the strategy employed for the components is 
incorrect. The maximum surface shear stress criterion is used to ensure the durability of the CVT, where $\boldsymbol{\tau}_{\max }=\mathbf{0 . 3 0} \boldsymbol{p}_{\mathbf{0}} \geq \mathbf{0 . 5} \boldsymbol{\sigma}_{Y}$ [19]. In order to avoid the CVT in use near the yielding point a safety factor of 1.2 has been utilised in the simulation [20].

\section{Viscous Friction:}

Evans and Johnson [21] produced friction maps of different lubricant types, accounting for thermal and elastic effects in the lubricant film. The elastic effect of the lubricant is governed by the fluid's shear modulus as well as the elastic compliance of the surfaces. CVT lubricant traction is governed by the regime where non-linear viscosity is experienced. The maximum coefficient of friction is calculated as [22]: $\mu_{m}=0.87 \bar{\alpha} \bar{\tau}_{0}+1.74 \frac{\bar{\tau}_{0}}{\bar{p}} \ln \left\{\left\{\frac{1.2}{\bar{\tau}_{0} h_{0}}\left(\frac{2 k \eta_{0}}{1+9.6 \xi}\right)\right\}\right\}^{1 / 2}$

$\xi$ is a non-dimensional parameter:

$\xi=\frac{k}{h_{0}}\left(\frac{16 \bar{p} R^{\prime}}{\pi E^{\prime} k^{\prime} \rho^{\prime} C^{\prime} U}\right)^{1 / 2}$

To calculate the viscous friction the normal load is multiplied by the maximum coefficient of friction:

$F_{v}=W \times \mu_{m}$

\section{Boundary friction:}

A model created by Greenwood and Tripp [23] assumed a Gaussian height distribution of asperities over a rough surface, indicating the deformation mode, and the shape of the asperities can be neglected with respects to the loading of the surfaces in contact. The total friction within the conjunction is calculated is obtained as a result of the boundary and viscous shear components:

$f=f_{v}+f_{b}$

The load share carried by the asperities due to boundary friction, $f_{b}$ is:

$f_{b}=\tau_{0} A_{a}+\varsigma W_{a}$

The eyring shear stress, $\tau_{0}$, is obtained using viscometry or an Atomic Force Microscope in wet Lateral Force Microscopy mode [24]. The asperity load and contact area, $W_{a}$ and $A_{a}$ respectively, are obtained as:

$W_{a}=\frac{16 \sqrt{2}}{15} \pi(\zeta \kappa \sigma)^{2} \sqrt{\frac{\sigma}{\kappa}} E^{\prime} A F_{5 / 2}(\lambda)$ 
$A_{a}=\pi^{2}(\zeta \kappa \sigma)^{2} \sqrt{\frac{\sigma}{\kappa}} A F_{2}(\lambda)$

The Gaussian distribution below is used to describe the interaction probability of the asperities. The roughness parameter is assumed to be $(\xi \beta \sigma)=0.055$, which is within the normal range for a steel surface $[23,25,26]$.

The Gaussian Distribution leads to below statistical functions which are used to calculate the asperity contact area and load $[18,19]$ :

$$
\begin{gathered}
F_{5 / 2}(\lambda)=\left\{\begin{array}{ll}
-0.004 \lambda^{5}+0.057 \lambda^{4}-0.296 \lambda^{3}+0.784 \lambda^{2}-1.078 \lambda+0.617 & ; \text { for } \lambda \leq 3 \\
0 & \text { f for } \lambda>3
\end{array}\right\} \\
F_{2}(\lambda)=\left\{\begin{array}{ll}
-0.0021) \\
0 & ; \text { for } \lambda \leq 3 \\
0 & \text { for } \lambda>3
\end{array}\right\}
\end{gathered}
$$

Film thickness:

Chittenden and Dowson produced and correlated theoretical expressions against experimental data in order verify and model the thickness of an EHL film in contact $[27,28]$ :

$h_{0}=4.31 U_{e}^{0.68} G_{e}^{0.49} W_{e}^{-0.073}\left\{1-e^{-1.23\left(\frac{R_{s}}{R_{e}}\right)^{2 / 3}}\right\} * R_{e}$

$R_{S}$ is the effective radius of curvature with respect to the direction of side leakage.

$\frac{1}{R_{S}}=\frac{\sin ^{2} \theta}{R_{x}}+\frac{\cos ^{2} \theta}{R_{y}}$

$R_{e}$ is the effective radius of curvature regarding the direction of lubricant entrainment.

$\frac{1}{R_{e}}=\frac{\cos ^{2} \theta}{R_{x}}+\frac{\sin ^{2} \theta}{R_{y}}$

The dimensionless parameters used are $G_{e}, U_{e}$ and $W_{e}$ :

$G_{e}=\frac{2}{\pi}\left(E^{\prime} \alpha\right)$

$U_{e}=\frac{\pi \eta_{0} \mathbf{V}}{4 E^{\prime} R_{e}}$

$W_{e}=\frac{\pi W}{2 E^{\prime} R_{e}^{2}}$

Spin and Powerloss Model:

The elliptical footprint of the contact between the roller and disk surface must be dimensioned in order to calculate the power loss due to spin. The major and minor axis of the ellipse can be found using [29]: 


$$
\begin{aligned}
& a_{e}=\left(\frac{6 \bar{k}^{2} \bar{\varepsilon} W R^{\prime}}{\pi \bar{k} E r}\right)^{1 / 3} \\
& b=\left(\frac{6 \bar{\varepsilon} W R^{\prime}}{\pi \bar{k} E r}\right)^{1 / 3}
\end{aligned}
$$

The maximum contact pressure within the ellipse is:

$P_{\text {max }}=\frac{3 W}{2 \pi a_{e} b}$

The mean contact pressures for points in the ellipse are:

$\bar{p}=\frac{W}{\pi a_{e} b}$

The ellipticity parameter is defined by:

$\bar{k}=1.0339\left(\frac{R_{x}}{R_{y}}\right)^{0.636}$

Brewe and Hamrock produced a numerical approximation to the simplified elliptical integral of the second kind [30]:

$\bar{\varepsilon}=1.0003+\frac{0.5968 R_{x}}{R_{y}}$

A [100x100] matrix (using polar coordinates) is used to calculate the 'radius' vector, to represent the ellipse, which are then multiplied by the angular spin velocity [31].

$\omega_{\text {spin }}=\left(\omega_{\text {disk }} \sin (f)\right)-\left(\omega_{\text {roller }} \cos (q)\right)$

$d V=r(i, j) * \omega_{\text {spin }}$

As the varying velocity vectors are now known the shear stress of each given point within the ellipse footprint can be computed:

$$
\begin{aligned}
\tau(i, j) & =\frac{\eta_{0} d V}{h_{0}} \\
F_{\text {vcell }} & =\tau(i, j) A_{\text {cell }}
\end{aligned}
$$

The power loss due to boundary and viscous friction can then be quantified by the following equation:

$P(i, j)=\sum_{i} \sum_{j}\left(F_{\text {vcell }}(i, j) * d V(i, j)\right)$ 


\section{Simulation Methodology}

\subsection{System Level Methodology}

The model was developed in the program Matlab 2015b. The simulation overview is described in Figure 4. 


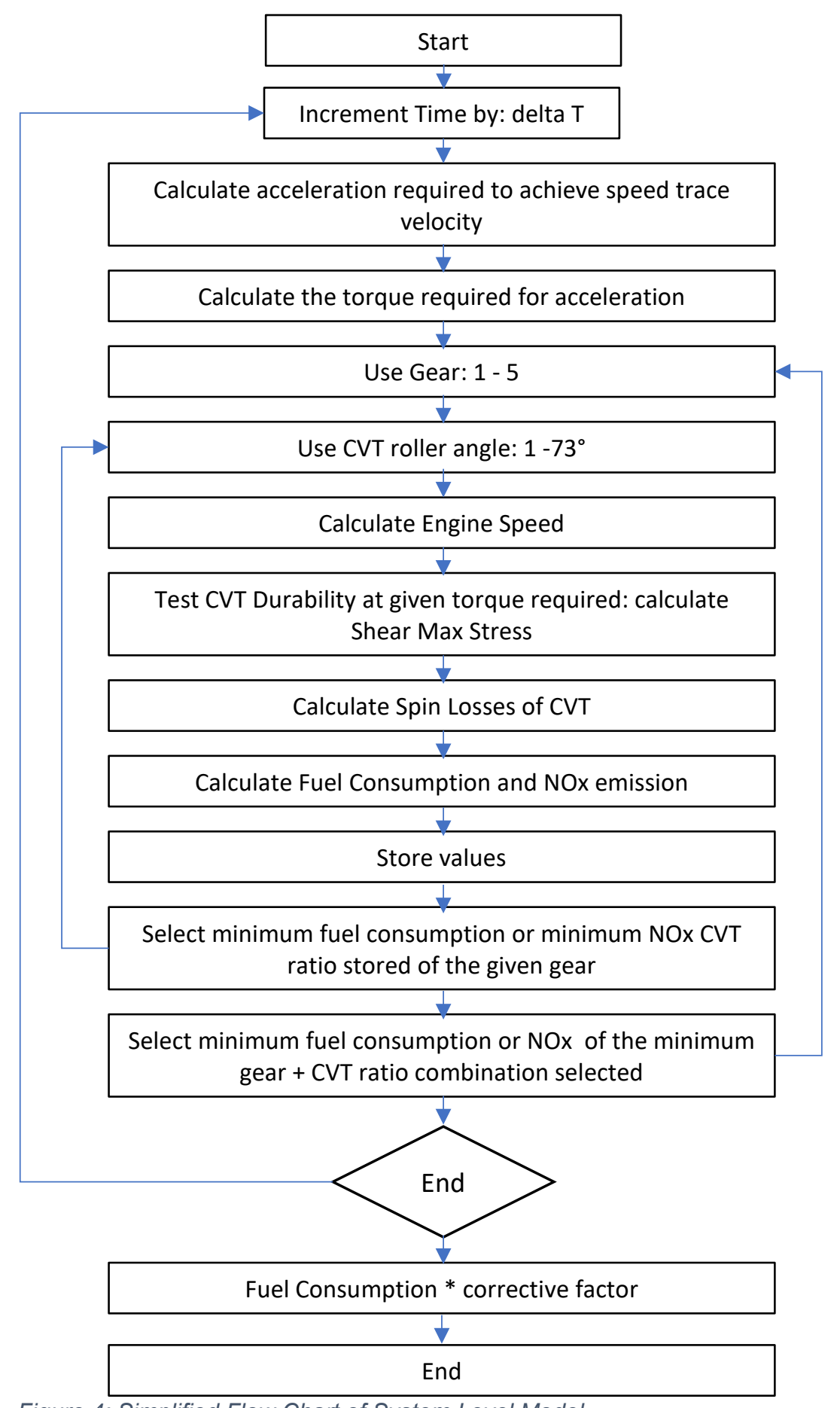

Figure 4: Simplified Flow Chart of System Level Model

\subsection{Component Level Methodology}

The component level simulation is described in Figure 5. 
Input:

Material Properties:

- Poisson Ratio Surface $1 \& 2$

- Young's Modulus Surface $1 \& 2$

- $\quad$ Yield Strength Surface 1 \&2

CVT Geometry:

- $\quad$ Radii - R12 R21 R22 R1 R3

- $\quad$ Angle $f \& q$

Lubrication Parameters

- Entry Viscosity EtaO

- $\quad$ Pressure- Viscosity Coefficient Alpha

- Shear Stress Limit TauLim0

Further Inputs:

- Speed of Roller and Disk

- Load W

- Input Torque T

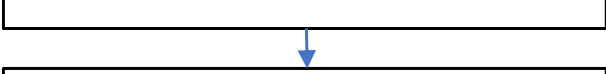

\section{Calculate:}

Entrainment Vector $V$

Angle f Entrainment Vector Theta

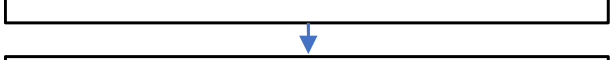

\section{Calculate:}

- $\quad E^{\prime}, R_{x} R_{y} R_{e} R_{s} R^{\prime}$

\section{Calculate:}

Ellipticity Parameter K bar

Simplified Elliptical Integral of the second Kind

Epsilon Bar

Ellipse Major Axis a

Ellipse Minor Axis b

Maximum Pressure $P_{\max }$

Average Pressure $P_{a v}$

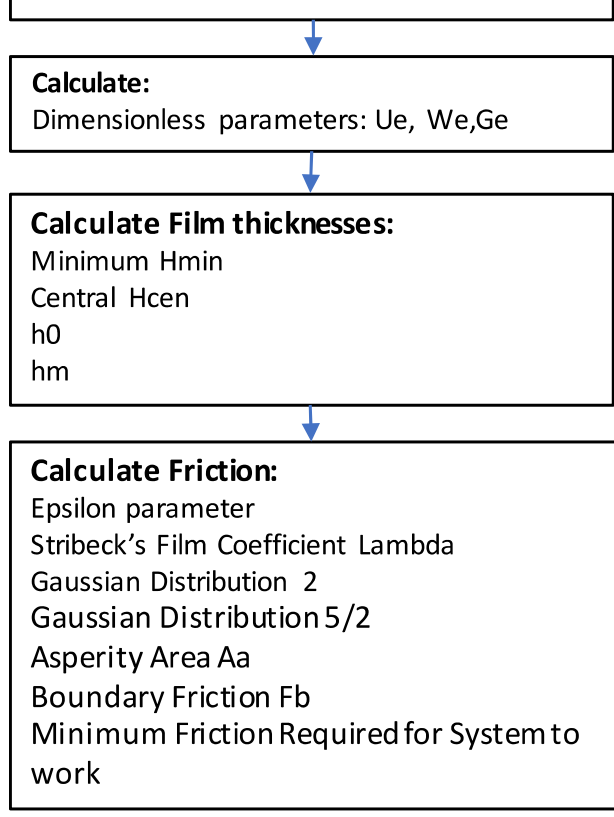

\section{End Pass Outputs:}

Max Power loss

Max Pressure Pmax

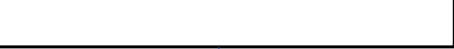

Calculate:

Sum of all Power to obtain total

Power loss from viscous and

boundary friction
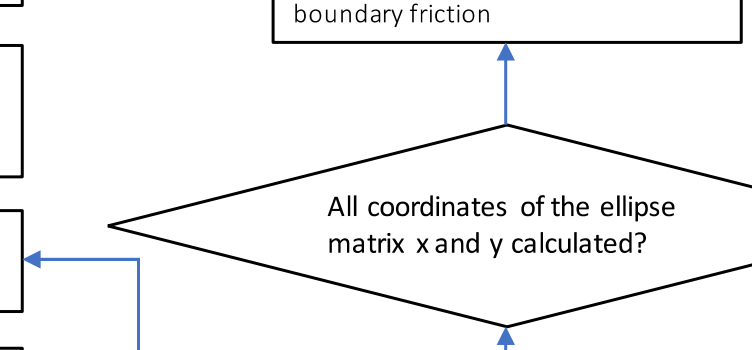

All coordinates of the ellipse matrix $x$ and $y$ calculated?
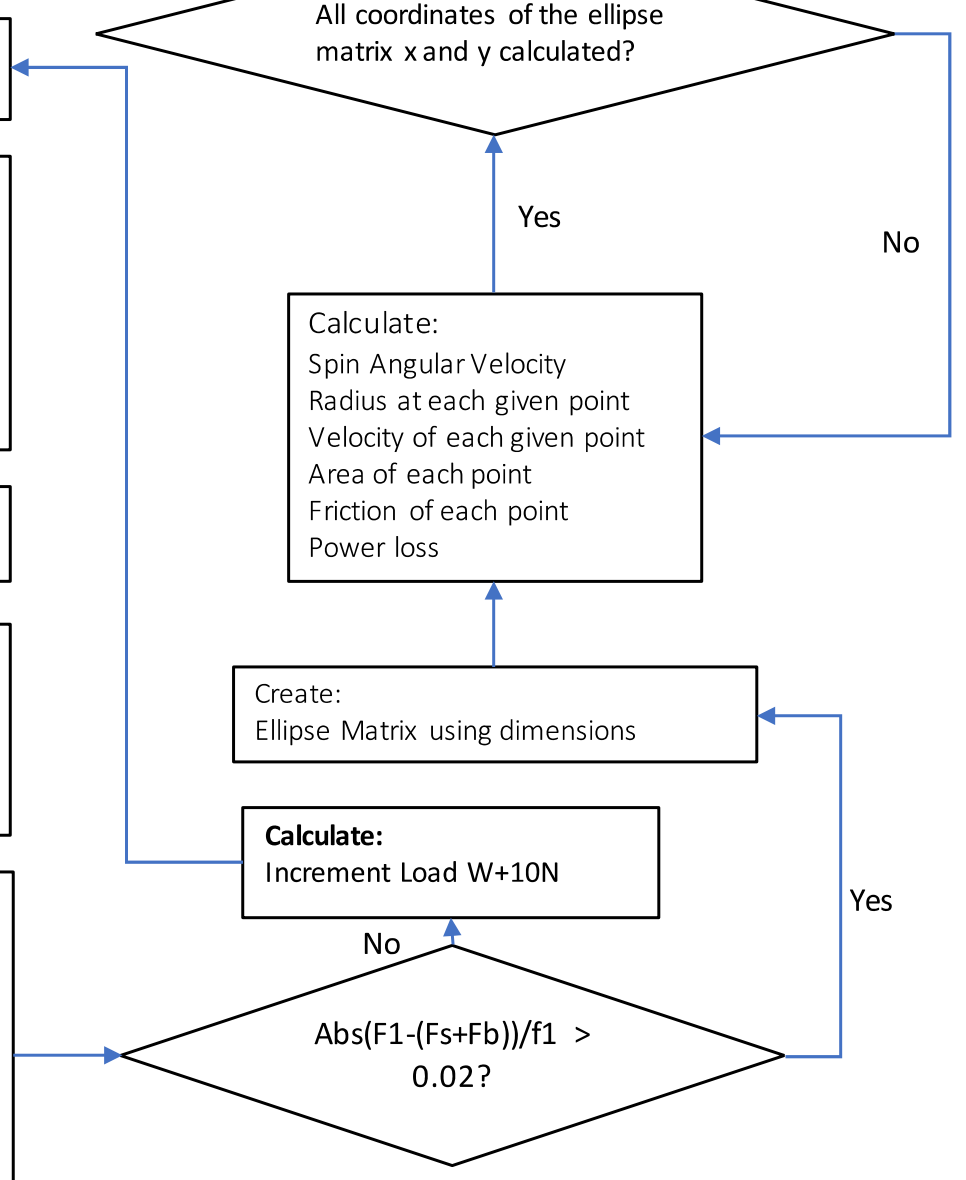

Figure 5: Component Level Flow Chart

\section{Vehicle and Engine Data}

The simulation uses vehicle data based on a C-segment 1.6L 4-cylinder petrol passenger vehicle [7]; however, for the current simulation the vehicle has been changed to rear wheel drive with a CVT in series with a 5 and 6 speed transmission. 
Original Vehicle Specification [7]

\begin{tabular}{|l|l|}
\hline Mass & $1330 \mathrm{~kg}$ \\
\hline Drag Coefficient & 0.325 \\
\hline Frontal Area & $2.01 \mathrm{~m}^{2}$ \\
\hline Tyre Radius & $0.2978 \mathrm{~m}$ \\
\hline Wheel Inertia & $0.74 \mathrm{~kg} \cdot \mathrm{m}^{2}$ \\
\hline Drive Type & RWD \\
\hline Emission Regulation & Euro 4 \\
\hline
\end{tabular}

Table 5: Original Engine Specification [7]

\begin{tabular}{|l|l|}
\hline Original Engine Specification [7] \\
\hline Type & 4 Stroke Spark Ignition \\
\hline Volume & $1.5968 \mathrm{~m}^{3}$ \\
\hline Engine Speed Max & $7000 \mathrm{rpm}$ \\
\hline Engine Idle Speed & $800 \mathrm{rpm}$ \\
\hline Engine Inertia & $0.1224 \mathrm{~kg} \cdot \mathrm{m}^{2}$ \\
\hline Cylinders & 4 \\
\hline
\end{tabular}

Table 6: Original Transmission Specification [7]

\begin{tabular}{|l|l|}
\hline Original Transmission Specification [7] \\
\hline Type & 5 Speed \\
\hline $1^{\text {st }}$ & Overall Gear Ratio \\
\hline $2^{\text {nd }}$ & 14.5183 \\
\hline $3^{\text {rd }}$ & 7.8892 \\
\hline $4^{\text {th }}$ & 5.4418 \\
\hline $5^{\text {th }}$ & 3.9548 \\
\hline
\end{tabular}




\begin{tabular}{|l|l|}
\hline \multicolumn{2}{|l|}{ Half Toroidal CVT Specification } \\
\hline Mass & $100 \mathrm{~kg}$ \\
\hline Speed Ratio & $0.61-0.93$ \\
\hline Number of Roller & 3 \\
\hline
\end{tabular}

To implement the CVT into the simulation additional mass had to be added to the kerb weight. An appropriate value of $100 \mathrm{~kg}$ was chosen based on [32]. 3 rollers were selected over just two, because this would help to distribute some of the load required to transmit the torque and improve the durability of the CVT. The BSFC and NOx emission maps are taken from Douglas et al [7]. The specific point on the BSFC and NOx maps at which the engine is operating at, is then multiplied by the instantaneous power [33].

Converting units from $\mathrm{g} / \mathrm{kWh}$ to $\mathrm{g} / \mathrm{s}$ allows the instantaneous fuel consumption and the NOx emissions to be calculated:

$$
\begin{aligned}
& \dot{m}_{f u e l}=B S F C \times P_{E n g}=\frac{B S F C \times\left(\frac{2 \pi}{60}\right) N_{E n g} T_{E n g}}{3.6 \times 10^{6}} \\
& \dot{m}_{N O x}=N O X \times P_{E n g}=\frac{N O X \times\left(\frac{2 \pi}{60}\right) N_{E n g} T_{E n g}}{3.6 \times 10^{6}}
\end{aligned}
$$

To correlate the simulation closer to experimental NEDC results of Douglas et al the assumptions in Equations 42 and 43 were made due to the engine cold start significantly changing the fuel consumption values, but not the NOx emissions:

$0<t<80(s) \quad \dot{m}_{\text {fuel,cold }}=4 \times \dot{m}_{\text {fuel,hot }}$

$80<t<230(s) \quad \dot{m}_{\text {fuel,cold }}=1.4 \times \dot{m}_{\text {fuel, hot }}$

\section{Results}

The presented shifting strategy employed by Oglieve et al. [12] to validate the model against the NEDC model was to shift at a fixed engine speed of $2450 \mathrm{rpm}$ using the original transmission and a 5-speed gearbox. The two shifting strategies applied in current simulations examine, for each given time step, all combinations of gear and CVT speed ratios as well as bypassing the CVT straight to the 5 speed gearbox via a clutch mechanism. The stored combinations that fulfil the criteria are then analysed 
to find the optimum solution with either minimum BSFC or NOx engine out emissions.

\subsection{Optimising 5-speed and 6-speed transmissions}

The original 5 speed gearbox in [12] was used as a baseline to compare what improvement other systems could gain in fuel economy and NOx emissions. The shifting strategy was to minimise the fuel consumption, this was done by calculating the fuel consumption for each gear and selecting the gear with the lowest fuel but within engine torque and speed constraints such as redline and keeping above a minimum engine speed. By optimising the 5- and 6-speed gearbox in tandem with using the new minimum fuel shifting strategy a significant increase in fuel economy is gained as $-7.02 \%$ and $-7.65 \%$ respectively as shown in Table 8 and 9 . The NOx emission reductions achieved by 5 and 6-speed gearboxes were both significant in comparison to the original shifting strategy with a $6.92 \%$ and $7.75 \%$ reduction respectively.

\begin{tabular}{|c|c|c|c|c|c|c|c|}
\hline \multirow[t]{2}{*}{ Transmission } & \multirow{2}{*}{$\begin{array}{l}\text { Shifting } \\
\text { Strategy }\end{array}$} & \multicolumn{6}{|c|}{ Final Gear Ratio } \\
\hline & & $1 \mathrm{st}$ & 2nd & $3 r d$ & 4th & 5th & $6^{\text {th }}$ \\
\hline $\begin{array}{l}\text { Original } 5 \\
\text { speed }\end{array}$ & Fixed & 14.518 & 7.889 & 5.442 & 3.955 & 3.258 & NA \\
\hline \multirow[t]{2}{*}{$\begin{array}{l}\text { Optimised } 5 \\
\text { speed }\end{array}$} & $\begin{array}{l}\text { Min } \\
\text { Fuel }\end{array}$ & 14.886 & 10.721 & 8.044 & 5.367 & 2.990 & NA \\
\hline & $\operatorname{Min} \mathrm{NO}_{\mathrm{x}}$ & 14.886 & 10.721 & 8.044 & 5.367 & 2.990 & NA \\
\hline \multirow[t]{2}{*}{$\begin{array}{l}\text { Optimised } 6 \\
\text { speed }\end{array}$} & $\begin{array}{l}\text { Min } \\
\text { Fuel }\end{array}$ & 14.886 & 11.256 & 9.115 & 6.973 & 4.832 & 2.990 \\
\hline & $\operatorname{Min} \mathrm{NO}_{\mathrm{x}}$ & 14.886 & 11.256 & 9.115 & 6.973 & 4.832 & 2.990 \\
\hline
\end{tabular}


Table 9: Results from original and optimised transmission [12]

\begin{tabular}{|c|c|c|c|c|c|}
\hline Transmission & $\begin{array}{l}\text { Shifting } \\
\text { Strategy }\end{array}$ & $\begin{array}{l}\text { Fuel } \\
\text { Consumption }\end{array}$ & $\begin{array}{l}\text { Fuel } \\
\text { Reduction }\end{array}$ & $\begin{array}{l}\mathrm{NO}_{x} \\
\text { Emission }\end{array}$ & $\begin{array}{l}\mathrm{NO}_{x} \\
\text { Reduction }\end{array}$ \\
\hline & & g & $\%$ & g & $\%$ \\
\hline $\begin{array}{ll}\text { Original } & 5 \\
\text { Speed } & \end{array}$ & Fixed & 641.19 & NA & 29.33 & NA \\
\hline \multirow[t]{2}{*}{$\begin{array}{l}\text { Optimised } 5 \\
\text { speed }\end{array}$} & $\begin{array}{l}\text { Min } \\
\text { Fuel }\end{array}$ & 596.16 & -7.02 & 27.44 & -6.46 \\
\hline & $\operatorname{Min} \mathrm{NO}_{x}$ & 617.90 & -3.63 & 27.30 & -6.92 \\
\hline \multirow[t]{2}{*}{$\begin{array}{l}\text { Optimised } 6 \\
\text { speed }\end{array}$} & $\begin{array}{l}\text { Min } \\
\text { Fuel }\end{array}$ & 592.13 & -7.65 & 27.32 & -6.85 \\
\hline & $\operatorname{Min} \mathrm{NO}_{x}$ & 610.56 & -4.78 & 27.06 & -7.75 \\
\hline
\end{tabular}

\subsection{CVT with a 5-speed and 6-speed transmissions}

In this section the optimised gear ratios of the 5 and 6 speed gearboxes together with a CVT implemented in series is obtained. The use of the CVT with the 5 and 6-speed gearbox showed some improvement in fuel consumption as shown in Table 10. However, the gearbox together with CVT does show a significantly increased capability to reduce the NOx emissions by $12.53 \%$. The remaining analysis is focused on the CVT with the optimised 5-speed gearbox.

Table 10: CVT with Optimised Transmissions Results
\begin{tabular}{|l|l|l|c|c|c|}
\hline Transmission & $\begin{array}{l}\text { Shifting } \\
\text { Strategy }\end{array}$ & $\begin{array}{l}\text { Fuel } \\
\text { Consumption }\end{array}$ & $\begin{array}{l}\text { Fuel } \\
\text { Reduction }\end{array}$ & $\begin{array}{l}\text { NOx } \\
\text { Emission }\end{array}$ & $\begin{array}{l}\text { NOx } \\
\text { Reduction }\end{array}$ \\
\cline { 3 - 6 } & & $\mathrm{g}$ & $\%$ & $\mathrm{~g}$ & $\%$ \\
\hline $\begin{array}{l}\text { CVT + } \\
\text { Optimised 5 } \\
\text { Speed }\end{array}$ & $\begin{array}{l}\text { Min } \\
\text { Fuel }\end{array}$ & 584.55 & -8.83 & 26.75 & -8.79 \\
\cline { 2 - 6 } & Min NOx & 587.62 & -8.35 & 26.00 & -11.34 \\
\hline $\begin{array}{l}\text { Optimised } 6 \\
\text { Speed }\end{array}$ & Min & 584.53 & -8.84 & 26.24 & -10.53 \\
\cline { 2 - 6 } & Fuel & & & & \\
\hline
\end{tabular}




\subsection{5-Speed: Minimum BSFC Strategy}

In Figure 6 and 7, the main advantage of using a CVT can be seen by shifting the engine operating region towards more fuel-efficient areas of the BSFC map. The CVT not only aids in allowing for a continuous selection of speed ratios, but also helps to boost the top speed ratios as shown at $\sim 3000 \mathrm{rpm}, 100 \mathrm{Nm}$. The operation of the CVT becomes clearer further in Figure 7 as it shows a 10 second time frame in which the CVT enables the engine speed to continually increase without having to shift up a gear, whilst moving into a more efficient area of the BSFC map.

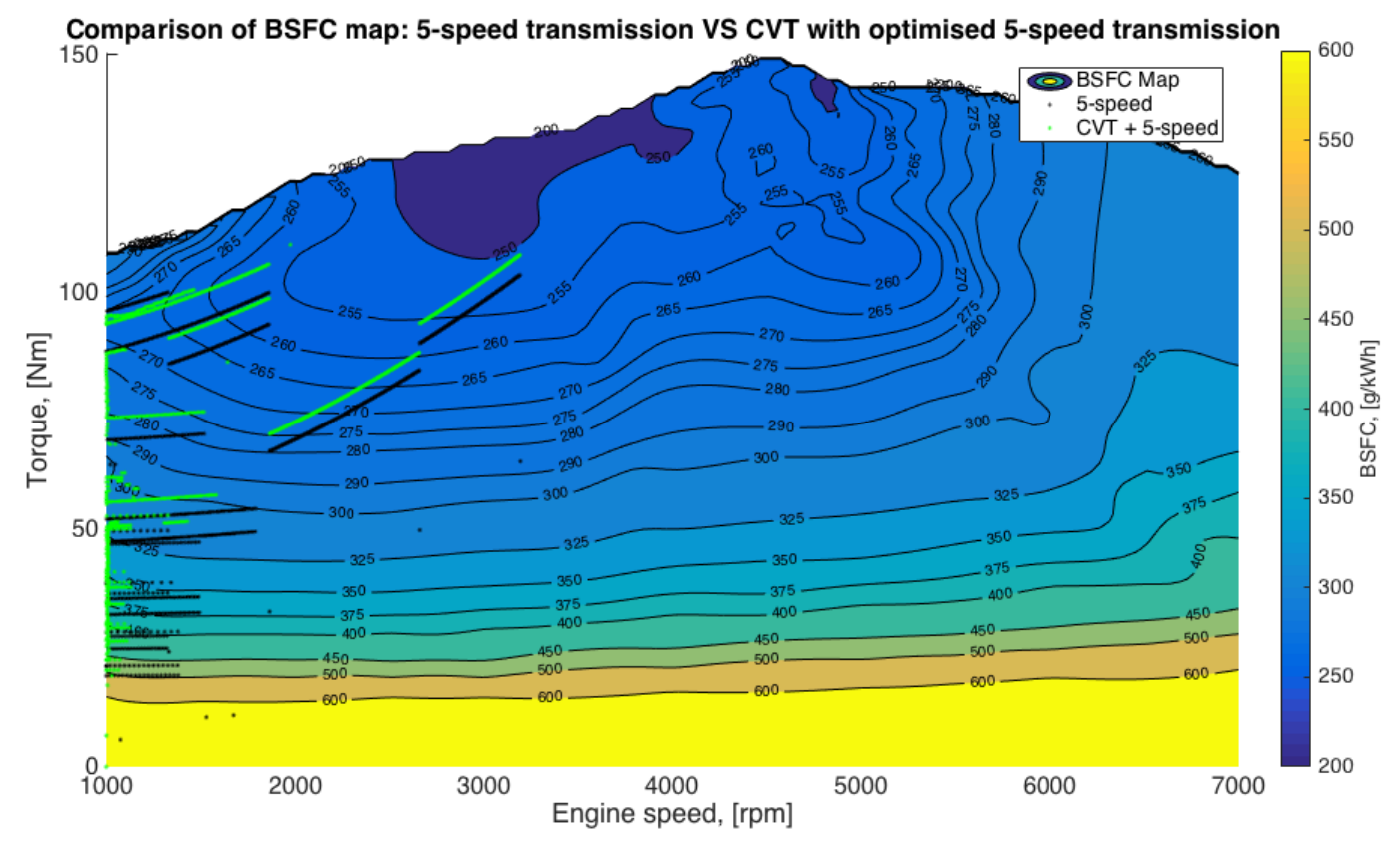

Figure 6: Minimum Fuel Strategy - BSFC map - optimised 5-speed CVT configuration comparison 


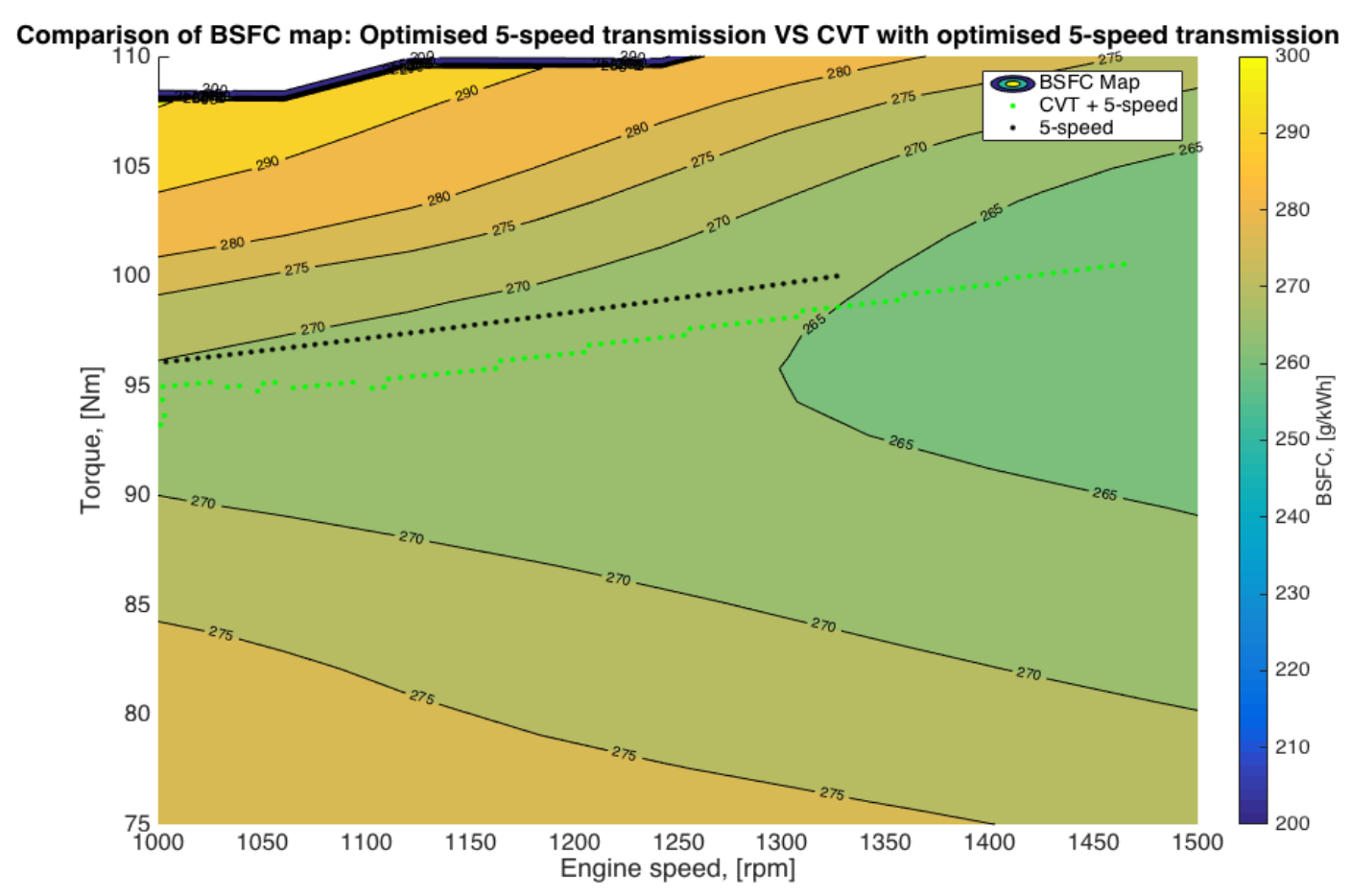

Figure 7: Minimum Fuel Strategy - BSFC map close up - optimised 5-speed CVT configuration comparison

The shifting point for the fifth gear using the minimum fuel strategy is shown to be delayed by using the CVT (Figure 8a). Furthermore, the CVT is shown to be used transiently at the lower vehicle speeds; however, when the top speeds of the NEDC are approached at a time $>800 \mathrm{~s}$, the CVT is only used at certain constant ratios.

Figure 9 shows how the reduced and increased fuel consumption and NOx emission due to CVT is calculated. It is shown that at a certain point the amount of increased fuel consumption and NOx due to the spin is higher than the gained value, hence the CVT can be bypassed. This will also increase the lifespan of the CVT by being able to avoid standing start situations. These instances are shown as broken regions in the Figure $8 \mathrm{~b}$. Figure 10 displays a comparison of where the standalone 5 -speed gearbox differs from the operation of the CVT with respect to overall fuel consumption and NOx emissions. The fuel consumption is shown to be reduced at urban, rural and motorway speeds whilst the CVT is in use. However, the fuel consumption reduction is most noticeable at time $>800 \mathrm{~s}$. This is again the advantage of using a higher top gear ratio at less transient motorway cruising sections of the NEDC. 

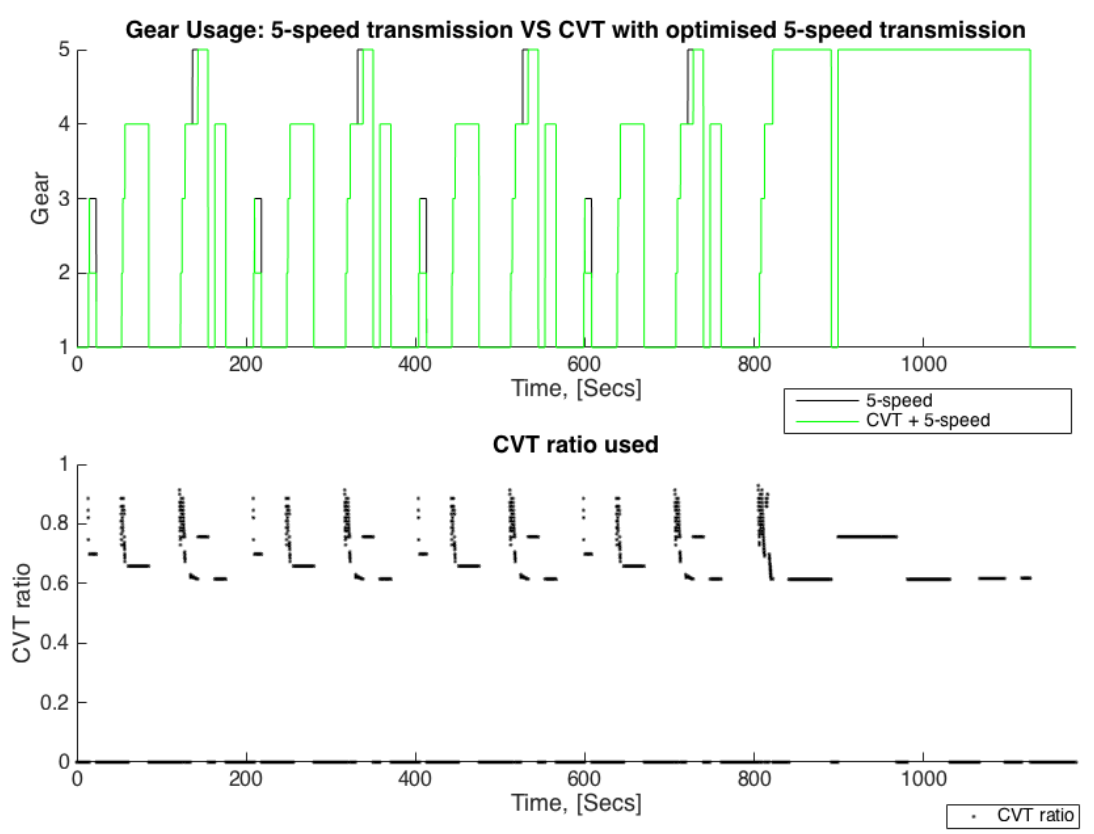

Figure 8: Minimum Fuel Strategy - (a) Gear and (b) CVT Usage optimised 5-speed configuration comparison
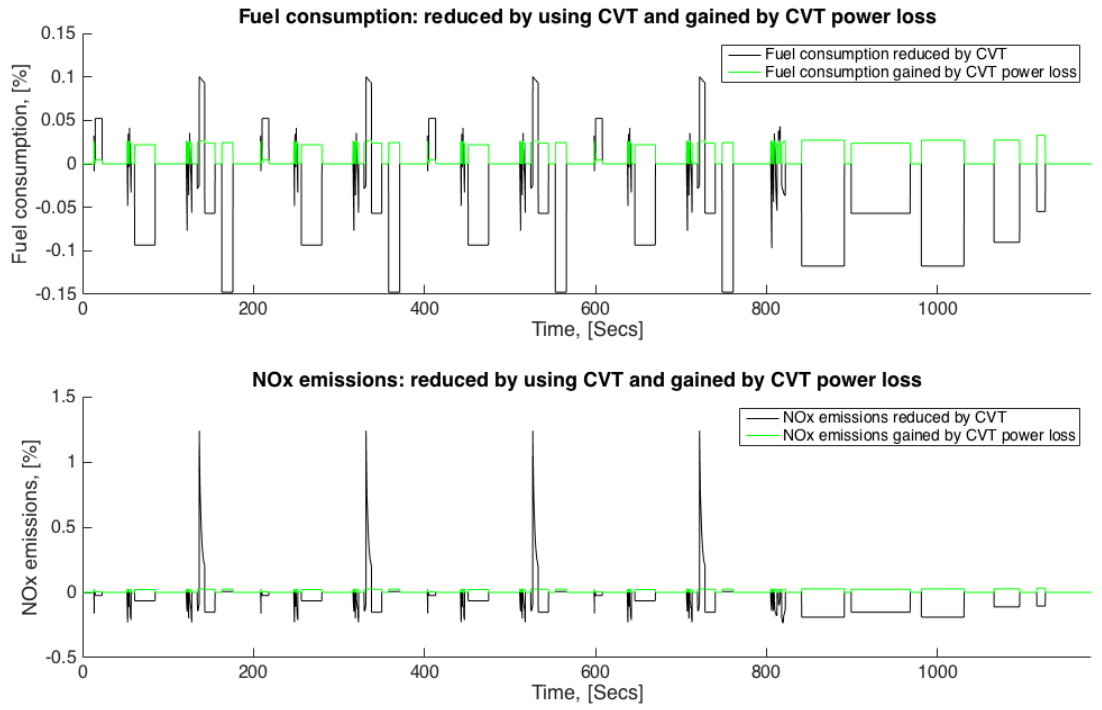

Figure 9: Minimum Fuel Strategy - (a) Fuel and (b) NOx increase and reductions - CVT usage 

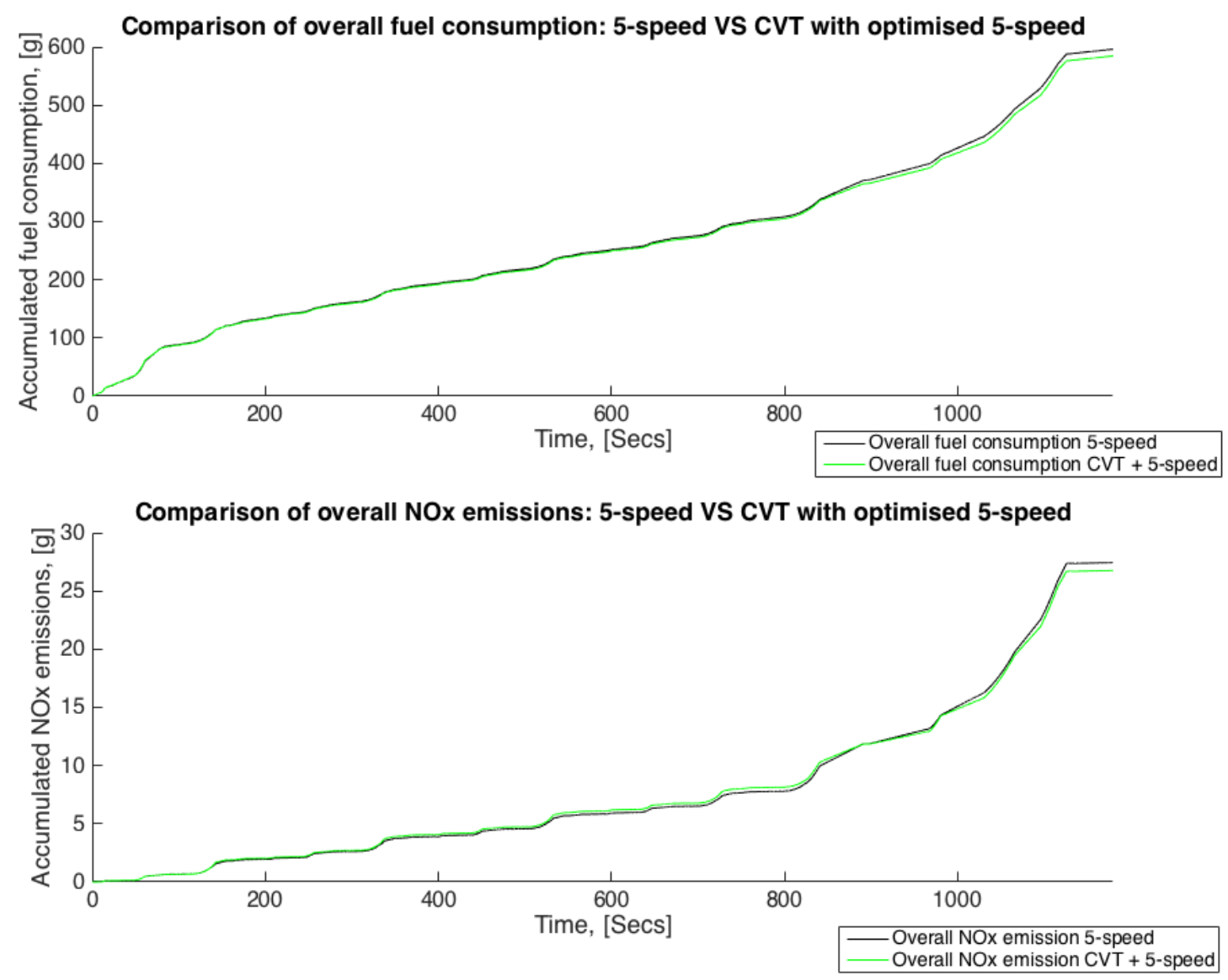

Figure 10: Minimum Fuel Strategy - Overall (a) fuel consumption and (b) NOx emissions - optimised 5-speed CVT configuration comparison

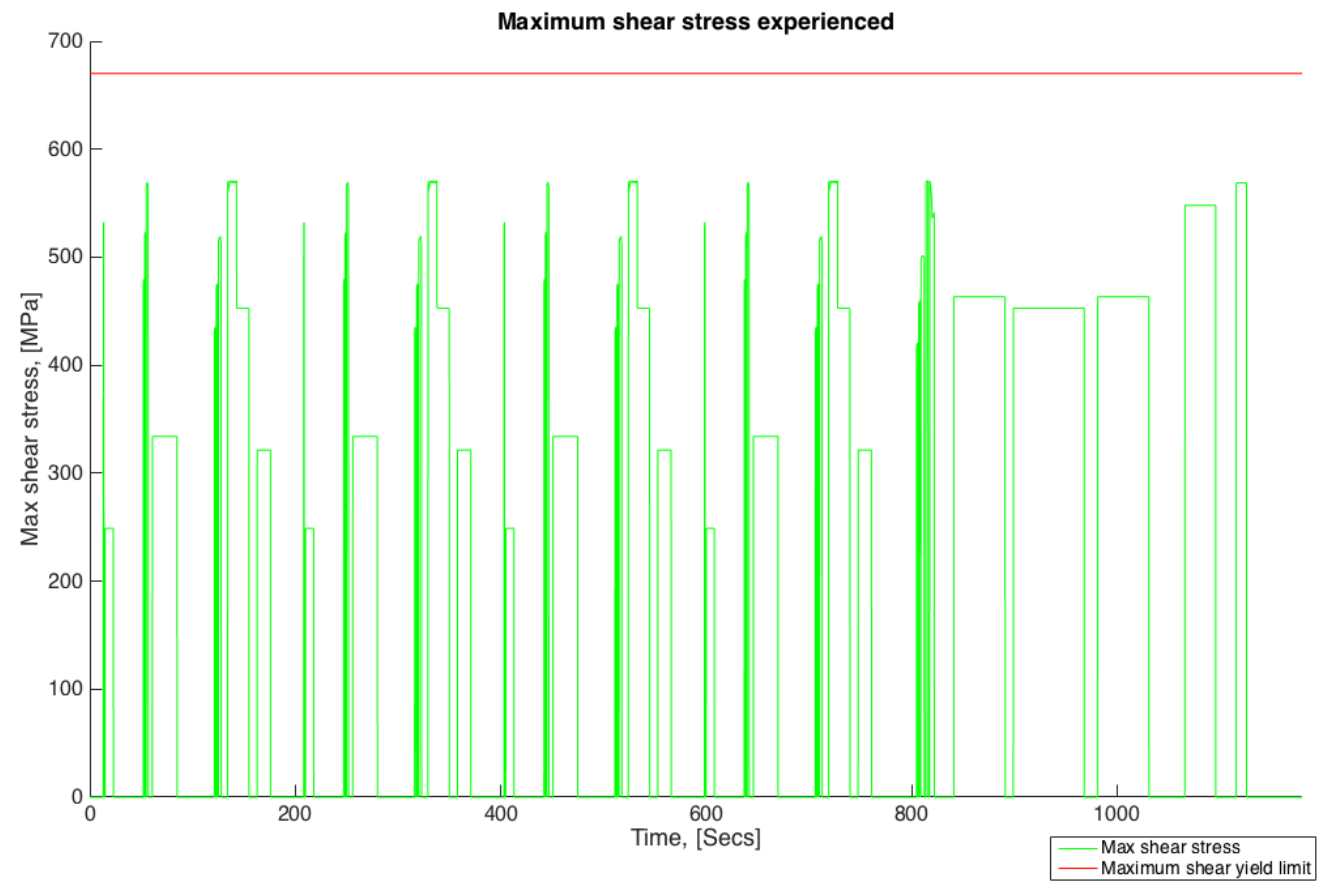

Figure 11: Minimum Fuel Strategy - Maximum shear stress - optimised 5-speed CVT configuration comparison 
It is shown, in Figure 11, that the shear maximum stress is not exceeded due to the safety factor of 1.2 employed. Although there does appear to be a significant amount of cyclic loading on the CVTs surfaces. This cyclic loading may become problematic in terms of the life span of the CVT.

\subsection{5-Speed: Minimum NOx Strategy}

Figure 12 shows that the CVT configured transmission is more able to achieve lower NOx emissions through the increased flexibility of transmission ratios. The CVT allows for a faster increase of engine speed in order to target the reduced NOx emissions as shown in Figure 13. Figure 13 shows the time period of 968.1 to 980.9 seconds of the NEDC cycle. The 5-speed transmission shows a linear increase of engine speed; however, the CVT transmission can continually reduce the speed ratio to its minimum of 0.63 . The CVT gives an advantage of reducing the NOx emissions over the 5 -speed transmission by $1.3 \mathrm{~g}$. Despite the gear shifting strategy targeted towards minimum NOx emissions, the fuel consumption was $11.63 \mathrm{~g}$ fewer than that of the 5-speed transmissions with a minimum fuel BSFC shifting strategy.

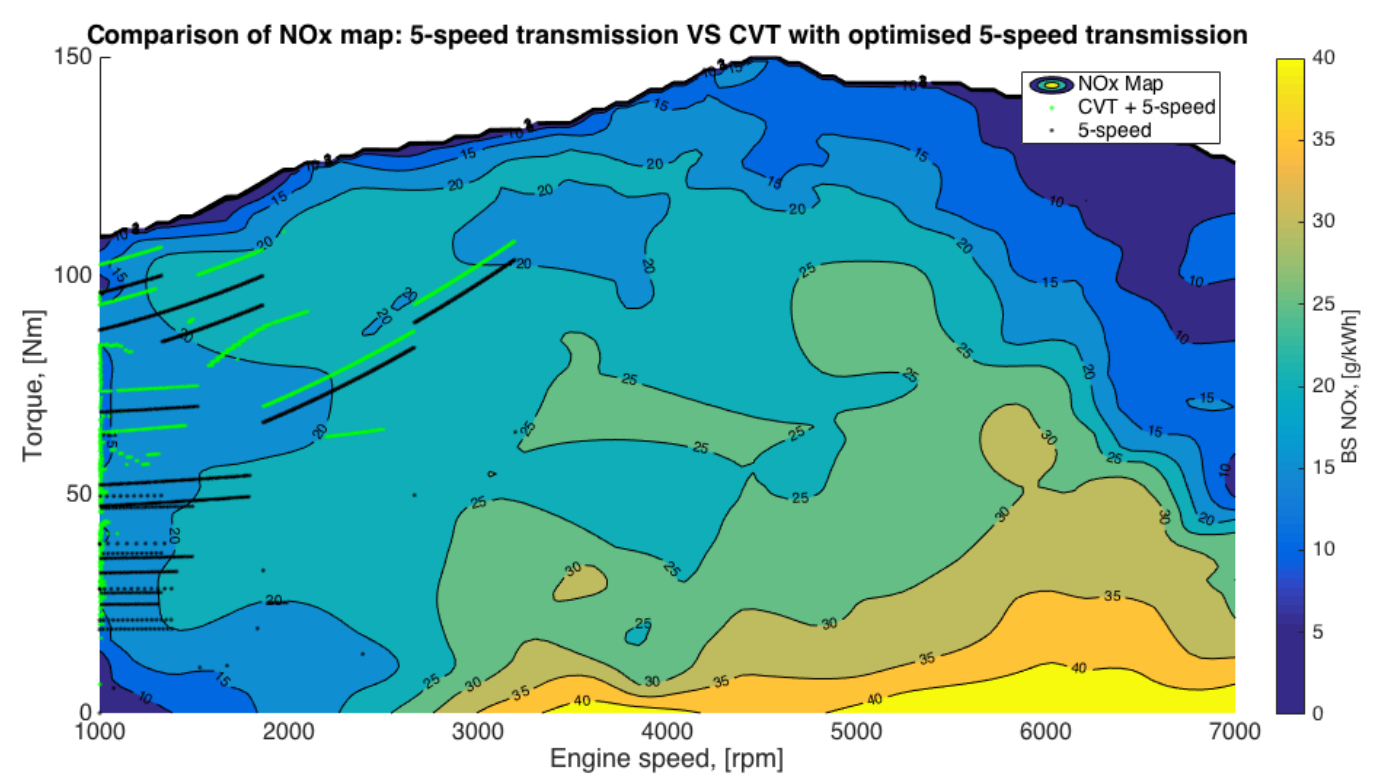

Figure 12: Minimum BSNOx strategy map - 5-speed transmissions VS CVT with optimised 5-speed transmission 


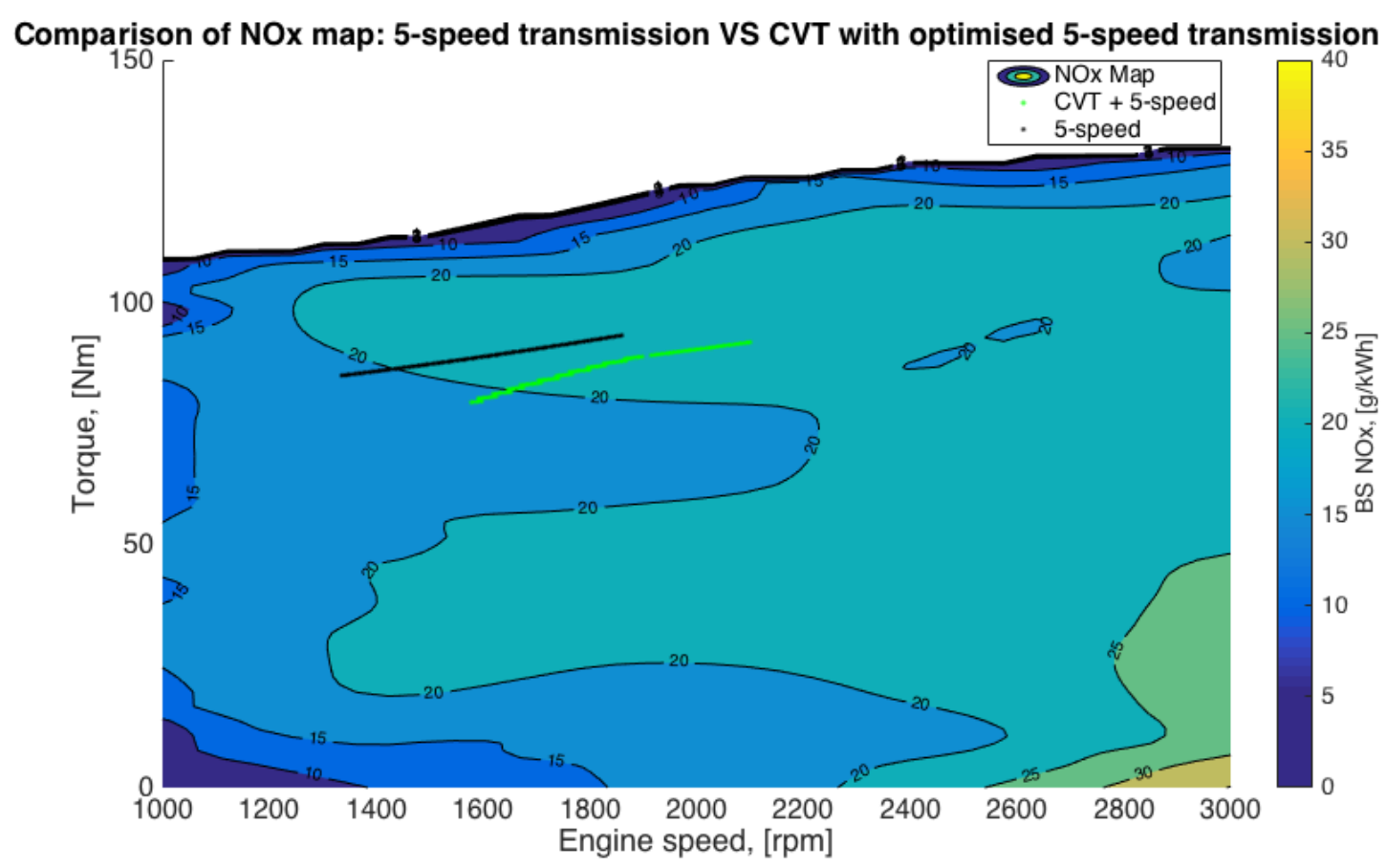

Figure 13: Minimum BSNOx strategy map close up - 5-speed transmissions VS CVT with optimised 5-speed transmission

\subsection{6-Speed transmission comparison}

The 6-speed transmission reduces the original shifting strategy of the 5-speed fuel and NOx emission values by $7.65 \%$ and $7.75 \%$ when using the different new gear shifting strategies. Despite this increase in performance from the 6-speed gearbox, due to an increase in discrete gear ratios, it still does not possess the flexibility of the CVT with a 5-speed transmission.

\section{Conclusion}

The paper details a novel approach in using a CVT mild hybrid transmission with two gear shifting strategies to optimise fuel consumption and NOx emissions and implement the use of a power loss model of a half toroidal CVT. The performance of a vehicle is examined over the NEDC to analyse the use of different shifting strategies and transmission types. The simulation makes use of a power loss model to demonstrate that a half toroidal CVT, in spite of issues regarding their internal inefficiency, can improve the fuel economy and NOx emissions of a vehicle.

The 5 and 6-speed transmissions were optimised to achieve the objective of best fuel economy and reduced NOx emissions. The optimised configurations were then adopted into the series CVT arrangement. This produced an $8.83 \%$ improvement in fuel economy and an $11.34 \%$ reduction in NOx emissions. Furthermore, the CVT 
configuration reduced the fuel consumption and NOx emissions in comparison to a conventional 6 -speed gearbox by $1.18 \%$ and $3.59 \%$ respectively. With increasingly more stringent emission regulations for internal combustion engines, the CVT should be considered for its capabilities of increasing the range of operating region at any given instance on the BSFC and BSNOx map over a standard 6-speed transmission. 


\section{Nomenclature}

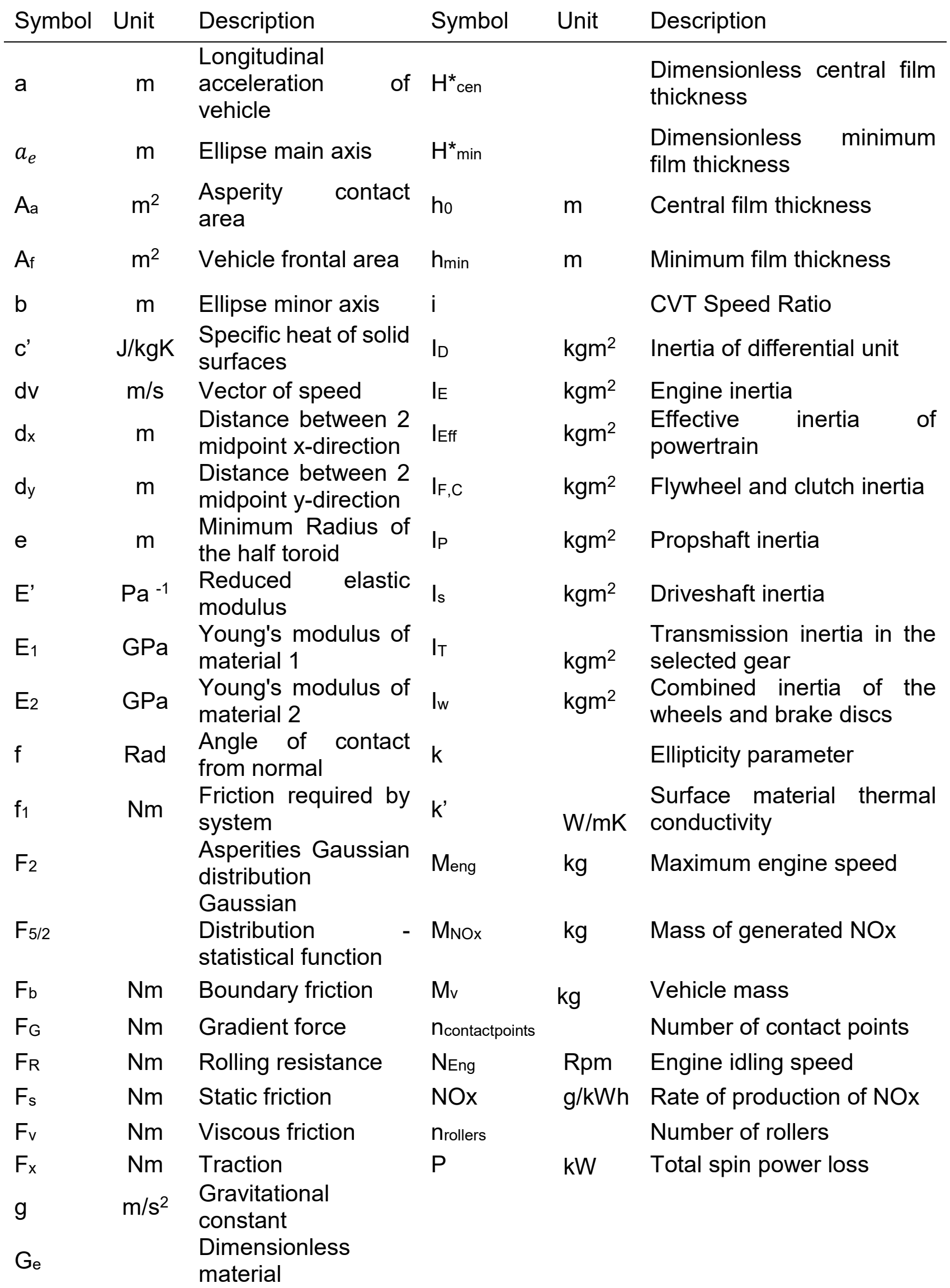




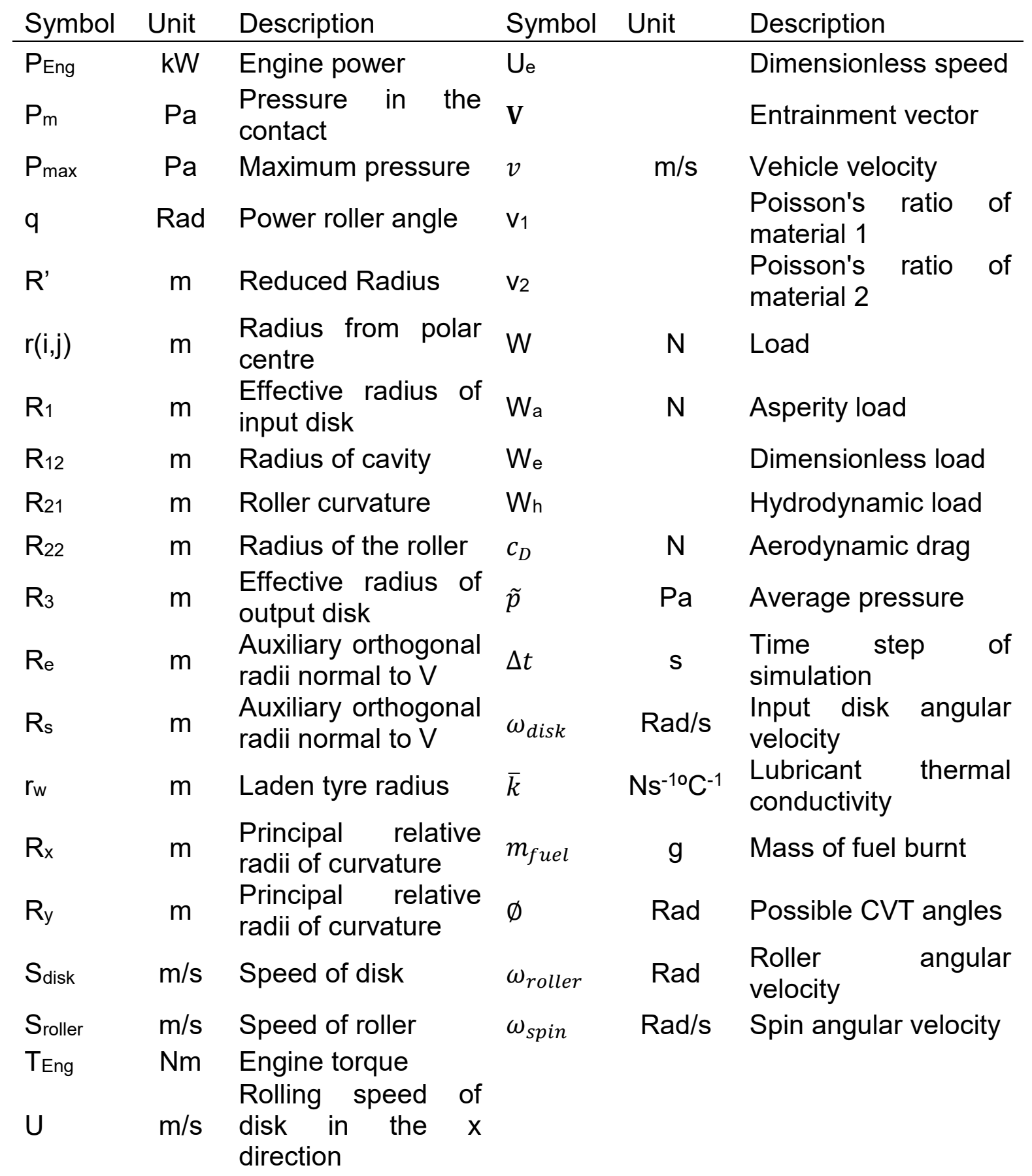


Greek Symbols

\begin{tabular}{|c|c|c|}
\hline Symbol & Unit & Description \\
\hline$\eta$ & & Overall Powertrain Efficiency \\
\hline$\theta_{\text {road }}$ & ${ }^{\circ} \mathrm{C}$ & Slope of hill \\
\hline$\mu$ & & Rolling resistance coefficient \\
\hline$\rho$ & $\mathrm{kg} / \mathrm{m}^{3}$ & Air density \\
\hline$\alpha$ & $\mathrm{Pa}^{-1}$ & Pressure-viscosity coefficient \\
\hline $\bar{\alpha}$ & $\mathrm{Pa}^{-1}$ & Average pressure coefficient \\
\hline$\beta$ & $\mathrm{m}$ & Average asperity tip radius \\
\hline$\varepsilon$ & $(-)$ & $\begin{array}{l}\text { Slope of the lubricant limiting shear stress-pressure } \\
\text { dependence }\end{array}$ \\
\hline $\bar{\varepsilon}$ & $(-)$ & Simplified elliptical integral \\
\hline $\bar{\eta}$ & Pa.s & Average viscosity \\
\hline$\eta_{0}$ & Pa.s & Entry viscosity of the lubricant \\
\hline$\lambda$ & $(-)$ & Stribeck's oil film parameter \\
\hline$\lambda_{c r}$ & $(-)$ & Critical Stribeck's parameter \\
\hline$\mu_{m}$ & $(-)$ & Maximum coefficient of friction \\
\hline$\sigma$ & $\mathrm{m}$ & Composite RMS surface roughness \\
\hline$\rho^{\prime}$ & $\mathrm{kg} / \mathrm{m}^{3}$ & Surface material density \\
\hline$\tau$ & $\mathrm{N} / \mathrm{m}^{2}$ & Shear stress \\
\hline$\tau(\mathrm{i}, \mathrm{j})$ & $\mathrm{N} / \mathrm{m}^{2}$ & Shear stress at a grid point \\
\hline$\tau_{L}$ & $\mathrm{~N} / \mathrm{m}^{2}$ & Limiting shear stress \\
\hline$\tau_{0}$ & $\mathrm{~N} / \mathrm{m}^{2}$ & Eyring shear stress \\
\hline$\overline{\tau_{0}}$ & $\mathrm{~N} / \mathrm{m}^{2}$ & Average Eyring stress \\
\hline$\theta_{v}$ & degrees & Angle of entrainment vector \\
\hline$\xi$ & $(-)$ & Parameter xi \\
\hline$\xi_{1}$ & $(-)$ & Asperity density per unit area \\
\hline$\varphi_{\text {Input }}$ & $(-)$ & Input Ratio \\
\hline$\varphi_{C V T}$ & $(-)$ & CVT Speed Ratio \\
\hline$\varphi_{\text {Gear }}$ & $(-)$ & Gear Ratio \\
\hline
\end{tabular}

\section{References}

[1] - VCA. Cars and Carbon Dioxide [Internet]. 2016 [cited 2016 Dec 1]. Available from: http://www.dft.gov.uk/vca/fcb/cars-and-carbon-dioxide.asp]

[2] - Holmberg K, Andrsson P, and Erdemir A, "Global Energy Consumption due to Friction in Passenger Cars", Tribology International, 47, 2012, pp. 221-234.

[3] Takagi Y, Itoh T, Muranaka S, liyama A, Iwakiri Y, Urushihara T, et al.

Simultaneous Attainment of Low Fuel Consumption High Output Power and Low Exhaust Emissions in Direct Injection SI Engines. 1998;(724). 
[4] - Fraser N, Blaxhill H. Engine Downsizing and the Application of Gasoline Direct Injection to a High Specific Output Turbocharged Engine. Fuel Econ Engine Downsizing Semin Proc. 2004;

[5] - Gheorghiu V. Ultra-Downsizing of Internal Combustion Engines. SAE Tech Pap. 2015;

[6] Ferrey P, Miehe Y, Constensou C, Collee V. Potential of a variable compression ratio Gasoline SI engine with very high expansion ratio and variable valve actuation. SAE Tech Pap. 2014;1(Livc):2014-01-1201.

[7] Douglas K, Milovanovic N, Turner J, Blundell D. Fuel Economy Improvement Using Combined CAI and Cylinder Deactivation (CDA)-An Initial Study. Sae Tech Pap Ser 2005-01-0110. 2005;2005(724):1-3.

[8] Mueller N, Strauss S, Tumback S, Goh G-C, Christ A. Next Generation Engine Start/Stop Systems: "Free-Wheeling." 2011;4(1).

[9] - Akbarzadeh S, Zohoor H. Optimizing the Geometry of a Half-Toroidal CVT. In: SAE Technical Paper Series. 2005.

[10] - Machida H, Itoh H, Imanishi T, Tanaka H. Design Principle of High Power Traction Drive CVT. In: SAE Technical Paper. 1995.

[11] - Carbone G, Mangialardi L, Mantriota G. A comparison of the performances of full and half toroidal traction drives. Mech Mach Theory. 2004;39(9):921-42.

[12] - Oglieve CJ, Mohammadpour M, Rahnejat H. Optimisation of vehicle transmission and shifting strategy for minimum fuel consumption and NOx emissions. 2016;

[13] - Medina Huerta I, Mohammadpour M, Rahnejat H. Analysis of Lubricated Contact in Continuously Variable Transmissions (CVT). 2016;

[14] - Guo YB, Liu CR. Mechanical Properties of Hardened AISI 52100 Steel in Hard Machining Processes. J Manuf Sci Eng. 2002;124(1):1.

[15] - Gabriel MG. Innovations in Automotive Transmission Engineering. Warrendale, PA: SAE International; 2003; 19-20

[16] - Gillespie TD. Fundamentals of Vehicle Dynamics. Warrendale, PA: Society of Automotive Engineers, Inc.; 1992. 
[17] - MIRA. No Title [Internet]. [cited 2016 Dec 11]. Available from:

http://www.horiba-mira.com/our-services/test-hills

[18] - Singh J, Srinivasa KVVR, Singh J. Selection of Gear Ratio for Smooth Gear Shifting. SAE Tech Pap. 2012 Sep 24;

[19] - Stachowiak G, Batchelor AW. Engineering Tribology. Elsevier Science; 2013.

[20] - Gohar R, Rahnejat H. Fundamentals of Tribology. Imperial College Press; 2008.

[21] - Evans CR, Johnson KL. Regimes of Traction in Elastohydrodynamic Lubrication. Proc Inst Mech Eng. 1985;200(6):313-22.

[22] - Evans CR, Johnson KL. The rheological properties of elastohydrodynamic lubricants. Proc Inst Mech Eng H. 1989;203(1):1-14.

[23] - Greenwood JA, Williamson JBP. Contact of Nominally Flat Surfaces. Proc R Soc A Math Phys Eng Sci. 1966;295(1442):300-19.

[24] - Leighton, M., Nicholls, T., De la Cruz, M., Rahmani, R. and Rahnejat, H., "Combined lubricant-surface system perspective: Multi-scale numericalexperimental investigation", Proc. IMechE, Part J: J. Engineering Tribology, 2017, 231(7), pp. 910-924.

[25] - Mohammadpour M, Theodossiades S, Rahnejat H, Kelly P. Transmission efficiency and noise, vibration and harshness refinement of differential hypoid gear pairs. Proc Inst Mech Eng Part K J Multi-body Dyn. 2014 Mar 1;228(1):19-33.

[26] - Teodorescu M, Balakrishnan S, Rahnejat H. Integrated Tribological Analysis within a Multi- physics Approach to System Dynamics. In: Tribology and Interface Engineering Series. 2005. p. 725-37.

[27] - Chittenden RJ, Dowson D. Elastohydrodynamic film thickness in concentrated contacts Part 1 : experimental investigation for lubricant entrainment aligned with the major axis of the contact ellipse. Proc Inst Mech Eng Part C J Mech Eng Sci. 1986;200(3):219-26.

[28] - Chittenden RJ, Dowson D. Elastohydrodynamic film thickness in concentrated contacts Part 2: correlation of experimental results with elastohydrodynamic theory. Proc Inst Mech Eng Part C J Mech Eng Sci. 1986;200(3):219-26. 
[29] - Hamrock BJ, Dowson D. Isothermal elastohydrodynamic lubrication of point contacts. III - Fully flooded results. J Tribol. 1977;99(2):264-75.

[30] - Brewe DE, Hamrock BJ. Simplified solution for point contact deformation between two elastic solids. NASA Tech Memo. 1976;(June):8.

[31] - Nabil AA. Torque capacity and contact efficiency of a half toroidal continuously variable transmissions. Chinese J Mech Eng (English Ed. 2004;17(3):457.

[32] - Shinojima T, Toyoda T, Miyata S. Development of the Next-Generation HalfToroidal CVT with Geared Neutral and Power-Split Systems for $450 \mathrm{Nm}$ Engines. SAE Tech Pap. 2004;2004-40-00.

[33] - J.B H. Internal Combustion Engine Fundamentals. 1st ed. New York: McGraw Hill; 1988. 